\title{
Coagulation and fibrinolysis in hyperparathyroidism secondary to vitamin D deficiency
}

Laura P B Elbers ${ }^{1,2}$, Marije Wijnberge ${ }^{1,2,3}$, Joost C M Meijers ${ }^{4,5}$, Dennis C W Poland ${ }^{6}$, Dees P M Brandjes ${ }^{1,2}$, Eric Fliers ${ }^{7}$ and Victor E A Gerdes ${ }^{1,2}$

${ }^{1}$ Department of Internal Medicine, Medical Center Slotervaart, Amsterdam, the Netherlands 2Department of Vascular Medicine, Academic Medical Center, University of Amsterdam, Amsterdam, the Netherlands ${ }^{3}$ Laboratory of Experimental Intensive Care and Anesthesiology, Academic Medical Center, University of Amsterdam, the Netherlands ${ }^{4}$ Department of Experimental Vascular Medicine, Academic Medical Center, University of Amsterdam, Amsterdam, the Netherlands 5 Department of Plasma Proteins, Sanquin Research, Amsterdam, the Netherlands ${ }^{6}$ Clinical Chemistry Laboratory, Medical Center Slotervaart, Amsterdam, the Netherlands

${ }^{7}$ Department of Endocrinology and Metabolism, Academic Medical Center, University of Amsterdam, Amsterdam, the Netherlands

Correspondence should be addressed to E Fliers: e.fliers@amc.uva.nl

\begin{abstract}
Introduction: Abnormal coagulation tests have been observed in patients with primary hyperparathyroidism (HPT) suggesting a prothrombotic effect of parathyroid hormone (PTH). Vitamin D deficiency (VIDD) is the most frequent cause of secondary HPT. Aim of our study was to investigate the influence of HPT secondary to moderate-to-severe VIDD and vitamin D replacement on the coagulation and fibrinolysis system.

Subjects and methods: Prospective cohort study of patients with vitamin $D<25 \mathrm{nmol} / \mathrm{L}$ with and without HPT, and a control group of patients on vitamin D suppletion. At baseline and after 2 months of vitamin D suppletion (900,000 IU in 2 months), endocrine and coagulation markers were measured.

Results: 59 patients with VIDD of which 34 had secondary HPT and 36 controls were included. After 2 months of suppletion, vitamin D increased by 399\% (VIDD with HPT), $442 \%$ (all patients with VIDD) and $6 \%$ (controls). PTH decreased by $34 \%$ (VIDD with HPT, $P<0.01$ for decrease), 32\% (all VIDD, $P<0.01$ ) and increased by $8 \%$ in the controls ( $P$-values: $<0.01$ for relative changes between VIDD with HPT or all VIDD patients vs controls). Relative changes in PT, aPTT, fibrinogen, Von Willebrand factor, factors VII, VIII and $\mathrm{X}$, thrombin generation, TAFI, clot-lysis time and D-dimer were not different between patients with VIDD with HPT or all VIDD vs controls.

Discussion: Secondary HPT due to VIDD does not have a prothrombotic effect. In contrast with previous reports, PTH does not seem to influence coagulation or fibrinolysis, which is relevant because of the high prevalence of VIDD.
\end{abstract}
Key Words
- coagulation
- fibrinolysis
- parathyroid hormone
- secondary hyperparathyroidism
- vitamin D deficiency

\section{Introduction}

An effect on markers of coagulation and fibrinolysis has been hypothesized for hyperparathyroidism as primary hyperparathyroidism is associated with an increased risk of cardiovascular (CV) morbidity and mortality (1, 2, 3, 4). Many known CV risk factors, such as hypertension, dyslipidemia and metabolic syndrome, have been reported in primary hyperparathyroidism $(4,5,6)$. A recent review summarizing the cardiovascular manifestations of primary hyperparathyroidism underlined the conflicting results of studies investigating the physiological effects
Endocrine Connections (2018) 7, 325-333 
of parathyroid hormone (PTH) and parathyroidectomy on, amongst others, endothelial dysfunction (4). In our current study, the objective was to study the direct effect of PTH on markers of coagulation and fibrinolysis since current literature on this topic is conflicting. Until to date, 5 studies focused on PTH and markers of coagulation and fibrinolysis (Table 1) $(5,6,7,8,9)$. Four studies investigated patients with primary hyperparathyroidism and some, but not all, indicated that this condition is associated with increased plasma levels of Factor (F) VII, FX, D-dimer, tissue plasminogen activator (t-PA) and plasminogen activator inhibitor-1 (PAI-1) compared to healthy controls $(5,6,7,8)$. Another study in healthy subjects found no significant relationship between hemostatic factors and serum PTH (9). Several methodological drawbacks limit any firm conclusions. Including a control group with healthy persons for example carries the risk of overestimating the difference when compared to patients with hyperparathyroidism since concomitant disease in those patients could also increase markers of coagulation and fibrinolysis. Besides, most of the current evidence does not allow us to assess the effect of increased and normalized values of PTH on coagulation within the same persons. Vitamin D deficiency is the most frequent cause of secondary hyperparathyroidism. In this study, we hypothesized that hyperparathyroidism secondary to vitamin D deficiency may be associated with procoagulant effects. This may be relevant given the high prevalence of hyperparathyroidism secondary to vitamin D deficiency.

\section{Subjects and methods}

\section{Study design}

We performed a prospective cohort study in patients with moderate-to-severe vitamin D deficiency. When diagnosed, blood was drawn for the measurement of vitamin D, PTH and coagulation and fibrinolysis markers. A second blood sample was drawn after 2 months of vitamin D suppletion. To control for blood handling, storage and seasonal influences we included a control group of patients with a previous vitamin D deficiency who were already using vitamin D (and thus were assumed to have normal levels of PTH and vitamin D) matched for age ( \pm 5 years) and gender. The study was performed between 12 September 2013 and 25 March 2015 according to the declaration of Helsinki, at the Department of Internal Medicine of the Medical Center Slotervaart. The study was approved by the local medical ethical committee of the Medical Center Slotervaart and all participants provided written informed consent.

Table 1 Studies investigating the effect of PTH on markers of coagulation and fibrinolysis.

\begin{tabular}{|c|c|c|c|c|c|}
\hline Author, year & $\begin{array}{l}\text { Study } \\
\text { design }\end{array}$ & Sample & Increased levels & No association & Conclusion \\
\hline Erem et al. (6) & Cohort & $\begin{array}{l}\text { Cases: } 23 \text { patients with } \\
\text { primary HPT } \\
\text { Controls: } 20 \text { age-matched } \\
\text { healthy controls }\end{array}$ & $\begin{array}{l}\text { Platelet count, FVII, } \\
\text { FX and D-dimer }\end{array}$ & $\begin{array}{l}\text { Fibrinogen, FV, FVIII, } \\
\text { FIX, vWF, AT, protein } \\
\text { C, protein S, t-PA, } \\
\text { PAI-1 }\end{array}$ & $\begin{array}{l}\text { Results suggest a } \\
\text { potential } \\
\text { hypercoagulable state }\end{array}$ \\
\hline Erem et al. (7) & Cohort & $\begin{array}{l}\text { Cases: } 24 \text { patients with } \\
\text { primary HPT } \\
\text { Controls: } 20 \text { age-, sex-, } \\
\text { and weight-matched } \\
\text { healthy controls }\end{array}$ & $\begin{array}{l}\text { t-PA, PAl-1, and } \\
\text { PAI-1/t-PA ratios } \\
\text { TFPI levels decreased }\end{array}$ & - & $\begin{array}{l}\text { Represents a potential } \\
\text { hypercoagulable and } \\
\text { hypofibrinolytic state }\end{array}$ \\
\hline $\begin{array}{l}\text { Chertok-Shacham } \\
\text { et al. (8) }\end{array}$ & Cohort & $\begin{array}{l}\text { Cases: } 35 \text { patients with } \\
\text { primary HPT } \\
\text { Controls: } 25, \text { age and } \\
\text { weight-matched } \\
\text { controls }\end{array}$ & PAI-1 & Fibrinogen and D-dimer & $\begin{array}{l}\text { Hypercoagulability may } \\
\text { be involved in the } \\
\text { pathogenesis of CVD } \\
\text { in these patients }\end{array}$ \\
\hline Farahnak et al. (5) & $\begin{array}{l}\text { Case- } \\
\text { control }\end{array}$ & $\begin{array}{l}\text { Cases: } 49 \text { patients with } \\
\text { primary HPT } \\
\text { Controls: } 49 \text { healthy } \\
\text { matched controls }\end{array}$ & - & $\begin{array}{l}\text { PAI-1, vWF, before and } \\
\text { after PTX in } \\
\text { comparison with } \\
\text { controls }\end{array}$ & $\begin{array}{l}\text { No differences as } \\
\text { regards biomarkers } \\
\text { predicting CVD }\end{array}$ \\
\hline Jorde et al. (9) & Cohort & $\begin{array}{l}\text { Cases: } 206 \text { healthy } \\
\text { subjects }\end{array}$ & - & $\begin{array}{l}\text { t-PA, PAI-1, prothrom- } \\
\text { bin fragment } 1+2, \text { FVII }\end{array}$ & $\begin{array}{l}\text { No significant relations } \\
\text { between any of the } \\
\text { haemostatic factors } \\
\text { tested and serum PTH }\end{array}$ \\
\hline
\end{tabular}

HPT, hyperparathyroidism; F, factor; vWF, von Willebrand Factor; AT, antithrombin; t-PA, tissue-type plasminogen activator; PAI-1, plasminogen activator inhibitor-1; TFPI, tissue factor pathway inhibitor; CVD, cardiovascular disease; PTX, parathyroidectomy; PTH, parathyroid hormone.

@ 2018 The authors
Published by Bioscientifica Ltd

http://www.endocrineconnections.org

https://doi.org/10.1530/EC-17-0249

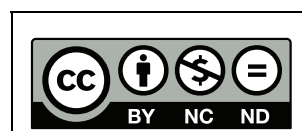

This work is licensed under a Creative Commons Attribution-NonCommercial-NoDerivatives 4.0 International License. 


\section{Study population}

All consecutive adult patients with moderate-to-severe vitamin D deficiency, defined as 25-OH-vitamin D blood levels of $<25 \mathrm{nmol} / \mathrm{L}$, were asked to participate in this study. These patients were identified by a daily notification by the local laboratory of all patients with vitamin D levels of $<25 \mathrm{nmol} / \mathrm{L}$. Patients with former vitamin D deficiency on vitamin D suppletion with colecalciferol were asked to participate as controls. In our center, the regular dosage to maintain normal vitamin $\mathrm{D}$ levels is a regimen of $50,000 \mathrm{IU}$ per month. For each patient with secondary hyperparathyroidism (defined as PTH $>10 \mathrm{pmol} / \mathrm{L}$ (upper limit of normal)) due to vitamin D deficiency, we included one control patient. These patients were retrieved by screening all patients using colecalciferol in the hospital using the electronic patient record system. Patients were excluded in case of pregnancy, acute and chronic renal disease (defined as eGFR $<45 \mathrm{~mL} / \mathrm{min}$ ), liver cirrhosis, granulomatosis (liver, lung, kidney, other), primary hyperparathyroidism, malabsorption syndromes, Von Willebrand disease, hemophilia, recent bariatric surgery ( $<13$ months before vitamin D deficiency diagnosis), any surgery in 3 months before inclusion, use of vitamin $\mathrm{K}$ antagonists or other anticoagulant therapy (except for low-molecular-weight heparin in a prophylactic dose and platelet aggregation inhibitors), unstable autoimmune disease (defined as erythrocyte sedimentation rate level above the upper limit of normal or recent change in medication dose) and the use of oral glucocorticoids. Controls were excluded if they had abnormal levels of vitamin D or PTH before inclusion (if measured due to patient care).

\section{Study procedures}

Study visits were scheduled between 08:00 and 11:00 h A total of $21 \mathrm{~mL}$ of venous blood was taken two times; at inclusion and after 2 months of vitamin D suppletion. Additional questions were asked about weight, height, medical history, ethnicity, smoking status and the use of (recently stopped) medication. This information was completed by reviewing the charts of all the patients. Endocrine disorders were stable diseases including diabetes. Patients with vitamin D deficiency were treated according to the following regimen: colecalciferol (vitamin D3) orally, 900,000 IU over 3 weeks (300,000 IU weekly) followed by a maintenance dose of $1000 \mathrm{IU} /$ day, aimed at achieving blood levels of 25-OH-D above $30 \mathrm{ng} / \mathrm{mL}(75 \mathrm{nmol} / \mathrm{L}))(10)$.

\section{Laboratory tests}

Blood samples were collected in a $3.5 \mathrm{~mL}$ serum tube (BD Vacutainer, Plymouth, UK) for direct assessment of levels of vitamin D, PTH, calcium, phosphate, creatinine, albumin and CRP, and in $3.5 \mathrm{~mL} 0.109 \mathrm{~mol} / \mathrm{L}$ (3.2\%) sodium citrate tubes for tests of coagulation and fibrinolysis (Greiner Bio-One, Kremsmünster, Austria). Citrated blood was immediately centrifuged, and the supernatant re-centrifuged, for $15 \mathrm{~min}$ at $3000 \mathrm{rpm}(1860 \boldsymbol{g})$ at $15^{\circ} \mathrm{C}$ to obtain platelet-poor plasma. Plasma was aliquoted and stored at $-80^{\circ} \mathrm{C}$ until further use. Measurement of coagulation and fibrinolysis parameters was performed in one batch at the Department of Experimental Vascular Medicine, Academic Medical Center, University of Amsterdam, Amsterdam, the Netherlands, after completion of the study. Analysis of PTH (reference value: $2.0-10.0 \mathrm{pmol} / \mathrm{L})$, vitamin $\mathrm{D}(>50 \mathrm{nmol} / \mathrm{L})$, calcium (2.20-2.60 mmol/L), phosphate $(0.70-1.50 \mathrm{mmol} / \mathrm{L})$, creatinine (70-110 $\mu \mathrm{mol} / \mathrm{L})$, albumin (35-50 g/L) and CRP $(<8 \mathrm{mg} / \mathrm{L})$ were performed on an Abbott Architect ci8200 (Abbott, Abbott Laboratories). During this study, Abbott Laboratories informed us that falsely elevated patient results were generated using the ARCHITECT Intact PTH Assay. Measurements of PTH were repeated in one batch in citrated plasma, after completion of the study with the use of a new reagent, at the local laboratory of the Medical Center Slotervaart. The intra- and inter-assay coefficients of variations (CVs) were 2.9-6.1\% and 3.0-6.4\%. Because the assay had not been validated by the manufacturer for use with citrated plasma, serum/citrated plasma studies were performed to characterize the correlation. Results in plasma were corrected for dilution with citrate. On the basis of the analysis of at least 30 samples, small systematic differences between serum and citrated plasma were observed, but Deming regression showed a highly significant association between serum and plasma levels of PTH (correlation coefficient $(\mathrm{R})=0.9754$. Prothrombin time (PT) (10.7-12.9s), activated partial thromboplastin time (aPTT) (25.0-38.0s), fibrinogen (1.9-4.0g/L), FVII activity (71-152\%), FVIII activity (63-173\%), FX activity $(66-125 \%)$ and D-dimer $(<1.00 \mathrm{mg} / \mathrm{L})$ were measured by BCS-XP (Siemens Healthcare). Von Willebrand Factor (VWF) antigen was measured by a homemade ELISA (antibodies from DakoCytomation, Denmark) (50-150\%). In vitro thrombin generation initiated by $1 \mathrm{pM}$ tissue factor was determined by calibrated automated thrombinography (CAT) (Thrombinoscope BV). The following parameters were derived from the thrombograms: lag time (1.5-3.2 min), peak thrombin (63-154\%) and endogenous This work is licensed under a Creative Commons
Attribution-NonCommercial-NoDerivatives 4.0 International License. 
thrombin potential (ETP) (65-146\%). Thrombinactivatable fibrinolysis-inhibitor (TAFI) activity (64-125\%) was measured by a Pentapharm TAFI kit. Clot-lysis times were obtained with a spectrophotometric method as described (11). Clot-lysis times were normalized to pooled normal plasma.

\section{Statistical analysis}

The main outcome of this study was comparison of coagulation parameters in patients with hyperparathyroidism secondary to vitamin D deficiency with these values after two months of vitamin D suppletion. Because some patients with vitamin D deficiency had normal levels of PTH at inclusion, our secondary outcome was the comparison of coagulation parameters in all patients with vitamin D deficiency, irrespective of their PTH level, with these values after two months of vitamin $\mathrm{D}$ suppletion. We planned to include 34 patients with vitamin D deficiency and secondary hyperparathyroidism and 34 control patients on vitamin D suppletion. This was based on the results of D-dimer and fibrinogen measurements in patients with primary hyperparathyroidism (5) and the assumption of an effect size of 0.5 (calculated as the difference of the means divided by the mean of the standard deviations), with a power of $80 \%$ and an alpha error of 0.05 . Performing a secondary analysis with all patients with vitamin D deficiency at baseline, regardless of their PTH level, gave us the opportunity to increase our sample size even more. If essential data were missing, for example, because drawn blood was hemolyzed, the measurement was repeated if possible. Otherwise, participants were replaced by a new participant to reach the intended power. The characteristics of the participants are expressed as median (interquartile range) or number (percentages) where appropriate; age and BMI are expressed as median (interquartile range) and the other characteristics as number (percentages). These characteristics were compared with the control group for both the patients with secondary hyperparathyroidism due to vitamin $\mathrm{D}$ deficiency as well as for the patients with normal PTH despite vitamin D deficiency by Mann-Whitney $U$ test or chi-square tests/Fisher's exact test, respectively. The parameters of coagulation and fibrinolysis are expressed as median (interquartile range). These parameters were compared before and after vitamin D suppletion by a Wilcoxon signed-rank test. The relative differences of coagulation parameters before and after vitamin D suppletion were compared between patients with vitamin $\mathrm{D}$ deficiency with hyperparathyroidism and all patients with vitamin D deficiency vs controls by a Mann-Whitney $U$ test. Statistical analysis was performed with the use of SPSS 21 software package (SPSS).

\section{Results}

\section{Participants, vitamin D and PTH}

Characteristics of participants are shown in Table 2 . During the study, 20 patients were excluded for the following reasons: pregnancy $(n=1)$, incompliance with vitamin D suppletion $(n=2)$, withdrawn informed consent/no-show visit $2(n=8)$, hemolyzed blood $(n=2)$, death $(n=1)$, prescription of oral corticosteroids $(n=1)$, change in methotrexate dose $(n=1)$, bariatric surgery $(n=1), \mathrm{GFR}<45 \mathrm{~mL} / \mathrm{min}(n=1)$ and control patients with vitamin D level $<40 \mathrm{nmol} / \mathrm{L}$ at baseline $(n=2)$. Excluding those patients, a total of 59 patients with moderate-tosevere vitamin D deficiency (vitamin D level $<25 \mathrm{nmol} / \mathrm{L}$ )

Table 2 General characteristics of participants at the time of inclusion.

\begin{tabular}{l} 
Parameter \\
\hline Age $^{\mathrm{a}}($ year) (median (IQR)) \\
$\mathrm{Gender}^{\mathrm{b}}(n)$ male \\
$\mathrm{BMI}^{\mathrm{a}}\left(\mathrm{kg} / \mathrm{m}^{2}\right)$ (median (IQR)) \\
Currently smoking ${ }^{\mathrm{b}}(n)$ \\
Medical history $^{\text {Cardiovascular disease }} \mathrm{c}(n)$ \\
Venous thromboembolism $^{\mathrm{b}}(n)$ \\
Diabetes $^{\mathrm{c}}(n)$ \\
Chronic kidney disease $^{\mathrm{b}}(n)$ \\
Endocrine disorders $^{\mathrm{c}}(n)$
\end{tabular}

\begin{tabular}{l} 
VIDD with SHPT $(n=38)$ \\
\hline $44(36-55)$ \\
5 \\
$29.4(26.4-36.0)$ \\
4 \\
11 \\
2 \\
10 \\
1 \\
14
\end{tabular}

\begin{tabular}{c} 
P value $^{\ddagger}$ \\
\hline 0.85 \\
0.54 \\
0.15 \\
0.51 \\
0.68 \\
0.49 \\
0.89 \\
1.00 \\
0.17
\end{tabular}

\begin{tabular}{c} 
VIDD $(n=59)$ \\
\hline $43(36-50)$ \\
12 \\
$29.4(25.5-37.2)$ \\
11
\end{tabular}

\begin{tabular}{c} 
P value $^{*}$ \\
\hline 0.49 \\
1.00 \\
0.10 \\
1.00 \\
\\
0.77 \\
0.52 \\
0.53 \\
1.00 \\
0.10
\end{tabular}

\begin{tabular}{c} 
Controls $(n=36)$ \\
\hline $44(37-57)$ \\
7 \\
$27.8(23.5-31.1)$ \\
6
\end{tabular}

Data are expressed as median (interquartile range) unless otherwise indicated. $P$ values were rounded to 2 decimals. Null hypotheses: when compared to the controls, for the patients with secondary hyperparathyroidism due to vitamin D deficiency, as well as for the patients with normal PTH level despite vitamin $D$ deficiency, there are no statistically significant differences in general characteristics.

${ }^{\ddagger} P$-values regard comparison vs. controls. ${ }^{M}$ Mann-Whitney $U$ test; ${ }^{b}$ Fisher's exact test; ${ }^{c}$ Chi-square test.

VIDD, vitamin D deficiency; SHPT, secondary hyperparathyroidism; N, number; PTH, parathyroid hormone; y, year; BMI, body-mass index.

(๑) 2018 The authors Published by Bioscientifica Ltd http://www.endocrineconnections.org

https://doi.org/10.1530/EC-17-0249

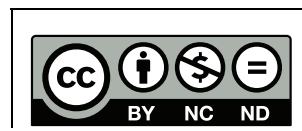

This work is licensed under a Creative Commons Attribution-NonCommercial-NoDerivatives 4.0 International License. 
and 36 control patients who were already using vitamin D suppletion at baseline completed 2 months of vitamin D replacement and underwent the second assessment after 2 months of follow-up. A total of 21 of the 59 patients with vitamin D deficiency had normal PTH levels at baseline $(\mathrm{PTH} \leq 10 \mathrm{nmol} / \mathrm{L})$.

There were no statistically significant differences in age, gender, BMI, smoking status and medical history when comparing the patients with secondary hyperparathyroidism due to vitamin D deficiency, respectively the patients with normal PTH levels despite vitamin D deficiency, to the control patients (Table 2).

Values of vitamin D, PTH, calcium, phosphate, creatinine, albumin and CRP and their relative changes after two months of vitamin D suppletion are depicted in Table 3. PTH levels decreased from 14.1 (12.1-17.2) to $9.3(7.2-11.3) \mathrm{pmol} / \mathrm{L}$ in the patients with secondary hyperparathyroidism due to vitamin $\mathrm{D}$ deficiency and from $12.0(7.7-15.7)$ to 7.4 (5.7-10.5) $\mathrm{pmol} / \mathrm{L}$ in all patients with vitamin $\mathrm{D}$ deficiency at baseline.
PTH decreased from $7.2(6.2-7.9)$ to $5.6(4.6-6.7) \mathrm{pmol} / \mathrm{L}$ in the patients with vitamin D deficiency but normal PTH levels at baseline. PTH levels did not change in the controls. In the patients with secondary hyperparathyroidism due to vitamin D deficiency, median (IQR) vitamin D level was 20 (18-24) nmol/L at baseline and 108 (92-140) nmol/L after two months of vitamin $\mathrm{D}$ suppletion. These values were similar for all patients with vitamin D deficiency, with and without hyperparathyroidism (vitamin D 20 (18-24) and 111 (94-162) nmol/L at baseline and after 2 months of vitamin D suppletion, respectively). Vitamin D levels did not change in the controls. Calcium and phosphate levels slightly increased within the normal ranges after 2 months of vitamin D suppletion in all patients with vitamin $\mathrm{D}$ deficiency at baseline, while these parameters did not change in the controls. Only in the controls, CRP levels were slightly increased after two months of vitamin D suppletion, within the reference range (1.5 (0.6-4.8) $\mathrm{mg} / \mathrm{L}$ at baseline compared to $2.1(0.9-5.9)$ after 2 months of vitamin D suppletion).

Table 3 Endocrinological parameters before and after 2 months of vitamin D suppletion.

\begin{tabular}{|c|c|c|c|}
\hline Parameter & At time of inclusion - median (IQR) & After 2 months of suppletion - median (IQR) & $P$ value $^{\text {a }}$ \\
\hline \multicolumn{4}{|l|}{ Vitamin D (nmol/L) } \\
\hline VIDD with SHPT & $20(18-24)$ & $108(92-140)$ & $<0.01$ \\
\hline VIDD & $20(18-24)$ & $111(94-162)$ & $<0.01$ \\
\hline Controls & $74(59-87)$ & $75(66-89)$ & 0.07 \\
\hline \multicolumn{4}{|l|}{ PTH (pmol/L) } \\
\hline VIDD with SHPT & $14.1(12.1-17.2)$ & $9.3(7.2-11.3)$ & $<0.01$ \\
\hline VIDD & $12.0(7.7-15.7)$ & $7.4(5.7-10.5)$ & $<0.01$ \\
\hline Controls & $6.7(5.3-9.0)$ & $7.3(6.0-9.7)$ & 0.13 \\
\hline \multicolumn{4}{|l|}{ Calcium (mmol/L) } \\
\hline VIDD with SHPT & $2.30(2.20-2.36)$ & $2.32(2.26-2.42)$ & $<0.01$ \\
\hline VIDD & $2.31(2.24-2.38)$ & $2.34(2.29-2.44)$ & $<0.01$ \\
\hline Controls & $2.33(2.29-2.41)$ & $2.35(2.27-2.43)$ & 0.65 \\
\hline \multicolumn{4}{|l|}{ Phosphate (mmol/L) } \\
\hline VIDD with SHPT & $1.0(0.9-1.1)$ & $1.1(1.0-1.2)$ & 0.01 \\
\hline VIDD & $1.0(0.9-1.1)$ & $1.1(0.9-1.2)$ & 0.02 \\
\hline Controls & $1.0(0.9-1.2)$ & $1.0(1.0-1.1)$ & 0.43 \\
\hline \multicolumn{4}{|l|}{ Creatinine $(\mu \mathrm{mol} / \mathrm{L})$} \\
\hline VIDD with SHPT & $65(57-70)$ & $65(58-72)$ & 0.14 \\
\hline VIDD & $65(59-72)$ & $65(60-72)$ & 0.13 \\
\hline Controls & $67(62-73)$ & $65(59-75)$ & 0.74 \\
\hline \multicolumn{4}{|l|}{ Albumin (g/L) } \\
\hline VIDD with SHPT & $37(35-38)$ & $36(34-40)$ & 0.49 \\
\hline VIDD & 37 (35-39) & $38(35-40)$ & 0.99 \\
\hline Controls & $38(36-40)$ & $38(36-40)$ & 0.99 \\
\hline \multicolumn{4}{|l|}{ CRP (mg/L) } \\
\hline VIDD with SHPT & $1.8(1.0-6.0)$ & $2.6(0.7-6.0)$ & 0.24 \\
\hline VIDD & $1.9(0.8-5.7)$ & $2.6(0.7-5.6)$ & 0.34 \\
\hline Controls & $1.5(0.6-4.8)$ & $2.1(0.9-5.9)$ & 0.01 \\
\hline
\end{tabular}

Data are expressed as median (interquartile range). $P$-values $<0.05$ are in bold. $P$ values were rounded to 2 decimals. Null hypotheses: there are no statistically significant differences between the time of inclusion and after two months of vitamin $D$ suppletion.

Wilcoxon signed rank test.

IQR, interquartile range; VIDD, vitamin D deficiency; SHPT, secondary hyperparathyroidism; PTH, parathyroid hormone; CRP, C-reactive protein.

$$
\begin{array}{lr}
\text { http://www.endocrineconnections.org } & \text { ○ } 2018 \text { The authors } \\
\text { https://doi.org/10.1530/EC-17-0249 } & \text { Published by Bioscientifica Ltd }
\end{array}
$$




\section{Coagulation and fibrinolytic parameters}

Parameters of coagulation, thrombin generation and fibrinolysis are shown in Table 4. After two months of vitamin D suppletion, PT, aPTT, fibrinogen, VWF, FVII, FVIII, ETP, D-dimer, TAFI and clot-lysis time did not change in the patients with vitamin D deficiency with secondary hyperparathyroidism. The same was true in all patients with vitamin D deficiency and in the controls. Only the change in FX in the patients with vitamin D deficiency and secondary hyperparathyroidism was statistically significantly different after two months of vitamin D suppletion ( $P$-value of 0.024 for an increase of $2.35 \%$ ). When analyzing all patients with vitamin $\mathrm{D}$ deficiency and the controls, the difference after two months of vitamin D suppletion was not statistically different. When comparing the relative change between baseline and 2 months follow-up between the patients with vitamin D deficiency and secondary hyperparathyroidism respectively all patients with vitamin $\mathrm{D}$ deficiency to the controls, there were no statistically significant differences except for FX ( $P$ value of 0.025 when comparing the relative change from baseline in the patients with vitamin $\mathrm{D}$ deficiency and secondary hyperparathyroidism to the controls).

\section{Discussion}

The aim of this study was to investigate the influence of hyperparathyroidism secondary to moderate-tosevere vitamin $\mathrm{D}$ deficiency and subsequent vitamin $\mathrm{D}$ replacement on the coagulation and fibrinolytic system. We hypothesized that after 2 months of vitamin D suppletion (and thus normalization of vitamin D and PTH), patients with moderate-to-severe vitamin D deficiency and secondary hyperparathyroidism would have lower levels of markers of coagulation and fibrinolysis when compared to before vitamin D suppletion. Because not all patients with moderate-to-severe vitamin D deficiency had increased levels of PTH at baseline, we made a distinction among patients with vitamin $\mathrm{D}$ deficiency with and without secondary hyperparathyroidism. In our study, parameters of coagulation and fibrinolysis did not change after two months of vitamin D suppletion despite a marked decrease in PTH levels in both the patients with vitamin D deficiency and secondary hyperparathyroidism at baseline $(n=38)$, and all patients with vitamin D deficiency at baseline $(n=59)$. Relative changes between baseline and
2 months of vitamin D suppletion did not differ between the patients with vitamin D deficiency and secondary hyperparathyroidism and the patients with vitamin D deficiency without secondary hyperparathyroidism, respectively, vs the control patients $(n=36)$. This indicates that, within this PTH range, there is no effect of PTH on the hemostatic system.

Only in FX, a small but statistically significant increase was detected in the patients with vitamin D deficiency and secondary hyperparathyroidism after two months of vitamin D suppletion, which was not in line with our hypothesis - we would expect a decrease - and likely attributed to multiple testing.

As a limitation of our study, one could argue that the levels of PTH in the patients with vitamin D deficiency and secondary hyperparathyroidism were not high enough at baseline or that the decrease in PTH after 2 months of vitamin D suppletion was not large enough to detect an effect of PTH on markers of coagulation and fibrinolysis. In the study by Chertok-Shacham and coworkers for example, patients with primary hyperparathyroidism had a mean PTH level of $136.2 \mathrm{ng} / \mathrm{L}$, compared to $36.2 \mathrm{in}$ the controls (8), which is in accordance with $14.3 \mathrm{pmol} / \mathrm{L}$ in the patients with primary hyperparathyroidism and $3.8 \mathrm{pmol} / \mathrm{L}$ in the controls. Indeed, with a median relative change from baseline in PTH of $-34 \%$ in our patients with secondary hyperparathyroidism due to vitamin D deficiency, we cannot rule out that a larger decrease in PTH may have an effect on markers of coagulation and fibrinolysis. However, the absence of any effect of such a decrease of PTH within the same persons on all the markers of coagulation and fibrinolysis measured in this study makes that possibility seem less likely.

Another limitation of this study is that PTH may influence additional humoral factors that lower markers of coagulation and fibrinolysis counteracting a stimulating effect of PTH per se. The receptor of PTH is markedly expressed in bone and kidney, but is also present in other tissues such as breast, skin, heart, blood vessels, pancreas, and others that are not regarded as classical PTH target tissues (12). This possibility might be investigated in future experimental studies involving administration of PTH. Besides, vitamin D could have direct or indirect effects on markers of coagulation. Various studies of differing quality investigated the effect of vitamin D levels and suppletion on markers of coagulation with conflicting results hindering any definitive conclusions (13, 14, 15, 16). However, the current evidence indicates that vitamin $\mathrm{D}$ deficiency does not lead to an increased risk of venous 
Table 4 Markers of coagulation and fibrinolysis before and after 2 months of vitamin D suppletion.

\begin{tabular}{|c|c|c|c|}
\hline Parameter & At time of inclusion - median (IQR) & After 2 months of suppletion - median (IQR) & $P$ value \\
\hline \multicolumn{4}{|l|}{ Coagulation } \\
\hline \multicolumn{4}{|l|}{ PT (s) } \\
\hline VIDD with SHPT & $11.6(10.9-12.1)$ & $11.7(10.9-12.1)$ & 0.93 \\
\hline VIDD & $11.5(11.0-12.1)$ & $11.6(11.1-12.1)$ & 0.90 \\
\hline Controls & $11.6(11.1-12.0)$ & $11.6(11.2-11.9)$ & 0.21 \\
\hline \multicolumn{4}{|l|}{ aPTT (s) } \\
\hline VIDD with SHPT & $32.0(29.6-33.7)$ & $31.2(29.0-33.7)$ & 0.07 \\
\hline VIDD & $31.9(30.2-34.4)$ & $31.9(29.6-33.7)$ & 0.06 \\
\hline Controls & $32.3(29.4-33.7)$ & $31.6(29.5-33.2)$ & 0.06 \\
\hline \multicolumn{4}{|l|}{ Fibrinogen ( $g / \mathrm{L})$} \\
\hline VIDD with SHPT & $3.4(2.9-4.0)$ & $3.3(2.9-4.1)$ & 0.49 \\
\hline VIDD & $3.4(2.8-4.0)$ & $3.4(2.9-4.1)$ & 0.18 \\
\hline Controls & $3.5(3.1-4.0)$ & $3.5(2.9-4.0)$ & 0.72 \\
\hline \multicolumn{4}{|l|}{ VWF (\%) } \\
\hline VIDD with SHPT & $117(101-158)$ & $121(95-184)$ & 0.14 \\
\hline VIDD & $125(103-162)$ & $127(105-176)$ & 0.21 \\
\hline Controls & $117(88-143)$ & $115(89-144)$ & 0.85 \\
\hline \multicolumn{4}{|l|}{ FVII (\%) } \\
\hline VIDD with SHPT & $108(86-142)$ & $104(88-138)$ & 0.81 \\
\hline VIDD & $114(87-140)$ & $112(88-136)$ & 0.52 \\
\hline Controls & $124(103-143)$ & $130(109-152)$ & 0.41 \\
\hline \multicolumn{4}{|l|}{ FVIII (\%) } \\
\hline VIDD with SHPT & $144(130-182)$ & $154(128-185)$ & 0.47 \\
\hline VIDD & $145(130-175)$ & $151(130-181)$ & 0.81 \\
\hline Controls & 139 (108-159) & $145(112-159)$ & 0.10 \\
\hline \multicolumn{4}{|l|}{$\mathrm{FX}(\%)$} \\
\hline VIDD with SHPT & $92(77-114)$ & $96(80-119)$ & 0.02 \\
\hline VIDD & $98(82-114)$ & $100(87-119)$ & 0.10 \\
\hline Controls & $99(84-116)$ & $99(87-114)$ & 0.26 \\
\hline \multicolumn{4}{|c|}{ Thrombin generation } \\
\hline \multicolumn{4}{|l|}{ Lag time (min) } \\
\hline VIDD with SHPT & $5.0(4.3-5.6)$ & $4.6(4.2-5.7)$ & 0.74 \\
\hline VIDD & $5.1(4.5-5.8)$ & $5.0(4.3-5.7)$ & 0.44 \\
\hline Controls & $4.9(4.5-5.6)$ & $5.0(4.3-5.7)$ & 0.25 \\
\hline \multicolumn{4}{|l|}{ Peak (\%) } \\
\hline VIDD with SHPT & $121(92-164)$ & $125(98-161)$ & 0.81 \\
\hline VIDD & $120(93-163)$ & $128(98-162)$ & 0.17 \\
\hline Controls & $120(104-185)$ & $128(110-166)$ & 0.55 \\
\hline \multicolumn{4}{|l|}{ ETP (\%) } \\
\hline VIDD with SHPT & $105(92-128)$ & $105(93-123)$ & 0.96 \\
\hline VIDD & $106(92-130)$ & $112(94-127)$ & 0.70 \\
\hline Controls & $106(94-138)$ & $111(95-131)$ & 0.47 \\
\hline \multicolumn{4}{|l|}{$\begin{array}{l}\text { Fibrinolysis } \\
\text { D-dimer (mg/L) }\end{array}$} \\
\hline VIDD with SHPT & $0.34(0.24-0.50)$ & $0.37(0.23-0.52)$ & 0.79 \\
\hline VIDD & $0.33(0.22-0.50)$ & $0.34(0.23-0.52)$ & 0.82 \\
\hline Controls & $0.31(0.18-0.56)$ & $0.30(0.20-0.55)$ & 0.78 \\
\hline \multicolumn{4}{|l|}{ TAFI } \\
\hline VIDD with SHPT & $85(78-93)$ & $84(76-96)$ & 0.88 \\
\hline VIDD & 85 (76-93) & $84(75-95)$ & 0.88 \\
\hline Controls & $90(81-100)$ & 91 (81-99) & 0.71 \\
\hline \multicolumn{4}{|l|}{$\mathrm{n}-\mathrm{CLT}(\%)$} \\
\hline VIDD with SHPT & 89 (76-109) & $91(79-106)$ & 0.41 \\
\hline VIDD & $96(81-116)$ & $94(84-109)$ & 0.57 \\
\hline Controls & $89(80-100)$ & $93(81-103)$ & 0.35 \\
\hline
\end{tabular}

Data are expressed as median (interquartile range). $P$-values $<0.05$ are in bold. $P$ values were rounded to 2 decimals. Null hypothesis: there are no statistically significant differences between the time of inclusion and after two months of vitamin $D$ suppletion.

ailcoxon signed rank test.

IQR, interquartile range; PT, prothrombin time; VIDD, vitamin D deficiency; SHPT, secondary hyperparathyroidism; aPTT, activated partial thromboplastin time; VWF, Von Willebrand Factor; F, factor; ETP, endogenous thrombin potential; TAFI, thrombin-activatable fibrinolysis-inhibitor; n-CLT, normalized clot lysis time.

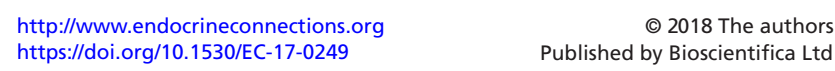


thrombosis $(17,18,19)$. Yet, in a secondary analysis of one of those studies, the risk of idiopathic venous thrombosis was lower in women randomized to calcium plus vitamin D (19) while another large study found a stepwise increasing risk of venous thromboembolism with decreasing tertiles of plasma 25-hydroxyvitamin D concentrations. However, an alternative explanation for this effect was the fact that a reduced 25-hydroxyvitamin $\mathrm{D}$ concentration is merely a marker of other common risk factors for venous thrombosis (20). To the best of our knowledge, there are no reports on studies investigating the risk of venous thrombosis in primary or secondary hyperparathyroidism.

The hypothesis that PTH influences the hemostatic system was based on several studies investigating the effect of primary hyperparathyroidism on markers of coagulation and fibrinolysis $(6,7,8)$. One explanation for these findings could be that these studies were performed in patients with primary hyperparathyroidism and that the observed results on the hemostatic system were not a direct effect of the increased levels of PTH, but as a result of clinical manifestations of primary hyperparathyroidism such as hypercalcemia. Such manifestations, including nephrolithiasis, could increase the inflammatory state and thereby result in a higher thrombotic tendency (21). Another explanation for not only the increased levels of coagulation and fibrinolysis, but also the increased rate of vascular events, in primary hyperparathyroidism could be that these suffer from dehydration more than healthy controls. Another explanation could be that in these 3 studies, markers of coagulation and fibrinolysis were only compared to a healthy control group thereby excluding the possibility to perform paired testing within the same patients (e.g., before and after parathyroidectomy). The only study reporting markers of coagulation and fibrinolysis (VWF and PAI-1) in patients with primary hyperparathyroidism before and after parathyroidectomy, did not find a difference in these markers (5).

In conclusion, we did not find an influence of hyperparathyroidism secondary to vitamin D deficiency on coagulation or fibrinolysis. For future research, the effect of tertiary hyperparathyroidism in which PTH levels are even higher remains to be investigated. Besides, to rule out an effect of comorbidities such as hypertension, inflammation and vascular calcification that are accompanied with tertiary hyperparathyroidism, the direct effect of exogenous PTH could be studied in healthy volunteers.

\section{Declaration of interest}

The authors declare that there is no conflict of interest that could be perceived as prejudicing the impartiality of the research reported.

\section{Funding}

This work was supported by the SKWOSZ (Foundation for Clinical Scientific Research Medical Center Slotervaart).

\section{Acknowledgements}

The authors thank all participants for their willingness to undertake this study. They thank the internists and geriatricians of the Medical Center Slotervaart for their help in identifying patients with vitamin D deficiency. They thank the co-workers of the Clinical Chemical Laboratory of the Medical Center Slotervaart for their help in laboratory procedures, with special thanks to Huib Bout, Ismaël Derraz and Natasja Huisman. They thank Wil Kopatz from the Department of Experimental Vascular Medicine, Academic Medical Center of the University of Amsterdam for her help in laboratory procedures.

\section{References}

1 Andersson P, Rydberg E \& Willenheimer R. Primary hyperparathyroidism and heart disease - a review. European Heart Journal 200425 1776-1787. (https://doi.org/10.1016/j. ehj.2004.07.010)

2 Hedback G \& Oden A. Increased risk of death from primary hyperparathyroidism - an update. European Journal of Clinical Investigation 199828 271-276. (https://doi.org/10.1046/j.13652362.1998.00289.x)

3 Kiernan TJ, O'Flynn AM, McDermott JH \& Kearney P. Primary hyperparathyroidism and the cardiovascular system. International Journal of Cardiology 2006113 E89-E92. (https://doi.org/10.1016/j. ijcard.2006.05.033)

4 Pepe J, Cipriani C, Sonato C, Raimo O, Biamonte F \& Minisola S. Cardiovascular manifestations of primary hyperparathyroidism: a narrative review. European Journal of Endocrinology $2017 \mathbf{1 7 7}$ R297-R308. (https://doi.org/10.1530/EJE-17-0485)

5 Farahnak P, Larfars G, Sten-Linder M \& Nilsson IL. Mild primary hyperparathyroidism: vitamin D deficiency and cardiovascular risk markers. Journal of Clinical Endocrinology and Metabolism 201196 2112-2118. (https://doi.org/10.1210/jc.2011-0238)

6 Erem C, Kocak M, Hacihasanoglu A, Yilmaz M, Saglam F \& Ersoz HO. Blood coagulation, fibrinolysis and lipid profile in patients with primary hyperparathyroidism: increased plasma factor VII and X activities and D-Dimer levels. Experimental and Clinical Endocrinology and Diabetes 2008 116 619-624. (https://doi.org/10.1055/s-2008-1065365)

7 Erem C, Kocak M, Nuhoglu I, Yilmaz M \& Ucuncu O. Increased plasminogen activator inhibitor-1, decreased tissue factor pathway inhibitor, and unchanged thrombin-activatable fibrinolysis inhibitor levels in patients with primary hyperparathyroidism. European Journal of Endocrinology 2009160 863-868. (https://doi.org/10.1530/ EJE-09-0069)

8 Chertok-Shacham E, Ishay A, Lavi I \& Luboshitzky R. Biomarkers of hypercoagulability and inflammation in primary hyperparathyroidism. Medical Science Monitor 200814 CR628-CR632. 9 Jorde R, Haug E, Figenschau Y \& Hansen JB. Serum levels of vitamin $\mathrm{D}$ and haemostatic factors in healthy subjects: the Tromso study. Acta Haematologica 2007117 91-97. (https://doi.org/10.1159/000097383)

10 Adami S, Romagnoli E, Carnevale V, Scillitani A, Giusti A, Rossini M, Gatti D, Nuti R, Minisola S \& Italian Society for Osteoporosis, 
Mineral Metabolism and Bone Diseases (SIOMMMS). Guidelines on prevention and treatment of vitamin D deficiency. Italian Society for Osteoporosis, Mineral Metabolism and Bone Diseases (SIOMMMS). Reumatismo 201163 129-147.

11 Bakhtiari K, Kamphuisen PW, Mancuso ME, Hamulyak K, Schutgens RE, Santagostino E \& Meijers JC. Clot lysis phenotype and response to recombinant factor VIIa in plasma of haemophilia A inhibitor patients. British Journal of Haematology 2013162 827-835. (https://doi.org/10.1111/bjh.12470)

12 Murray TM, Rao LG, Divieti P \& Bringhurst FR. Parathyroid hormone secretion and action: evidence for discrete receptors for the carboxylterminal region and related biological actions of carboxyl- terminal ligands. Endocrine Reviews 200526 78-113. (https://doi.org/10.1210/ er.2003-0024)

13 Topaloglu O, Arslan MS, Karakose M, Ucan B, Ginis Z, Cakir E, Akkaymak ET, Sahin M, Ozbek M, Cakal E, et al. Is there any association between thrombosis and tissue factor pathway inhibitor levels in patients with vitamin D deficiency? Clinical and Applied Thrombosis/Hemostasis 201521 428-433. (https://doi.org/10.1177/1076029613509477)

14 Stricker H, Tosi Bianda F, Guidicelli-Nicolosi S, Limoni C \& Colucci G. Effect of a single, oral, high-dose vitamin D supplementation on endothelial function in patients with peripheral arterial disease: a randomised controlled pilot study. European Journal of Vascular and Endovascular Surgery 201244 307-312. (https://doi. org/10.1016/j.ejvs.2012.06.023)

15 Saliba W, Awad K, Ron G \& Elias M. The effect of vitamin D supplementation on thrombin generation assessed by the calibrated automated thrombogram. Clinical and Applied Thrombosis/Hemostasis 201622 340-345. (https://doi.org/10.1177/1076029614556745)
16 Targher G, Pichiri I \& Lippi G. Vitamin D, thrombosis, and hemostasis: more than skin deep. Seminars in Thrombosis and Hemostasis 201238 114-124. (https://doi. org/10.1055/s-0031-1300957)

17 Folsom AR, Roetker NS, Rosamond WD, Heckbert SR, Basu S, Cushman M \& Lutsey PL. Serum 25-hydroxyvitamin D and risk of venous thromboembolism: the Atherosclerosis Risk in Communities (ARIC) Study. Journal of Thrombosis and Haemostasis 201412 1455-1460. (https://doi.org/10.1111/jth.12665)

18 Blondon M, Rodabough RJ, Budrys N, Johnson KC, Berger JS, Shikany JM, Raiesdana A, Heckbert SR, Manson JE, LaCroix AZ, et al. The effect of calcium plus vitamin D supplementation on the risk of venous thromboembolism. From the women's health initiative randomized controlled trial. Thrombosis and Haemostasis 2015113 999-1009. (https://doi.org/10.1160/TH1405-0478)

19 Andro M, Delluc A, Moineau MP, Tromeur C, Gouillou M, Lacut K, Carré JL, Gentric A \& Le Gal G. Serum levels of 25(OH)D are not associated with venous thromboembolism in the elderly population. A case-control study. Thrombosis and Haemostasis 2015115 169-175. (https://doi.org/10.1160/TH15-02-0148)

20 Brondum-Jacobsen P, Benn M, Tybjaerg-Hansen A \& Nordestgaard BG. 25-Hydroxyvitamin D concentrations and risk of venous thromboembolism in the general population with 18,791 participants. Journal of Thrombosis and Haemostasis 201311 423-431. (https://doi.org/10.1111/jth.12118)

21 Levi M, van der Poll T \& Buller HR. Bidirectional relation between inflammation and coagulation. Circulation 2004109 2698-2704. (https://doi.org/10.1161/01.CIR.0000131660.51520.9A)

Received in final form 15 December 2017

Accepted 9 January 2018

Accepted Preprint published online 9 January 2018 http://www.endocrineconnections.org https://doi.org/10.1530/EC-17-0249
() 2018 The authors Published by Bioscientifica Ltd

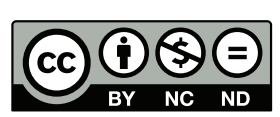

This work is licensed under a Creative Commons Attribution-NonCommercial-NoDerivatives 4.0 International License. 